\title{
Impact Signal Propagation Parameters to UMTS-LTE Handover
}

\author{
Maksum Pinem ${ }^{1}$, Chairunnisa FR. Tanjung ${ }^{2}$, Emerson P. Sinulingga ${ }^{3}$ and Suherman ${ }^{4}$ \\ \{maksum@usu.ac.id ${ }^{1}$, chairunnisatan91@gmail.com ${ }^{2}$ \} \\ ${ }^{1,2,3,4}$ Electrical Engineering Department, Universitas Sumatera Utara, Indonesia
}

\begin{abstract}
Handover mechanism is to maintain continues connection by migrating users from one to other channel within a base station or different ones. As wireless channel is heavily depending on signal propagation, the propagation parameters are important factors in handover decision. This papermodelsmobile node path through three base stations and analyses the propagation parameters impact on softhandover performance between UMTS and LTE networks. Simulation results on the designed model show that the greater the value of the velocity then the point of sampling that occurs will be less and the number of handover will be greater. Conversely, if the speed is lower than the sampling point that occurs will be more and the number of handover will be smaller. It is found that the speed at $10 \mathrm{~m} / \mathrm{s}$ is the best speed because the RSCP (Received Signal Code Power), and RSRP(Reference Signal Received Power) signal strength values are -99 $\mathrm{dBm}$ and $-111 \mathrm{dBm}$ respectively with the number of sampling points being 57 and the number of handing over is 2 times.
\end{abstract}

Keywords: Handover, Propagation Parameters, UMTS, LTE.

\section{Introduction}

The telecommunication development experiences tremendous improvement as demands on communication increases. Cellular networks rely on capacity and mobility(Marwan Al-Akaidi, 2015). Capacity improvement moves technology from UMTS (Universal Mobile Telecommunication System) to LTE (Long Term Evolution). However, even dough operators intent to migrate UMTS to LTE, the implementation deals with customer satisfaction (Kalbande, 2014)]. So as for solution, LTE is implemented gradually along with existing UMTS networks.

On the other hand, mobility with less disconnections and high speed switch requires sophisticated handover algorithm. The drawback on the system results customer dissatisfaction as speed and signal degrades when handover in progress. Signal strength and obstacles are the main problems (Sravani, Mesala., 2015).

In order to make sure that handover occurs smoothly, signal degradation and power threshold should be determined precisely (Wardana Lingga, 2010). Soft handover is preferred than the hard one as communication disconnection is less frequently (Halgamuge, 2006). Even dough, signal strength variations caused propagation and threshold for handover decision should be taken into consideration carefully. This paper models the soft handover from UMTS to LTE networks with three base stations involved. The paper also analyses the impact of propagation parameters to handover performance. 


\section{Method}

The propagation model describes the average propagation of signals in an area. The magnitude of these propagation losses varies according to the spectrum and the nature and the environment. Estimating the losses of the signal radio is very important. One of them is the losses generated by signal propagation. Loss of propagation is fairly difficult to predict. This loss is directly affected by the state of the environment surrounding the signal. Experts have produced some mathematical models that can provide good enough value to approach realworld circumstances. Among the radio signal propagation channel models are large-scale propagation models(Pinem, 2014). The system is modelled with three base stations as depicted in Figure 1, where mobile node moves from BTS1 to BTS 3. The three BTSs have the same transmitting power. Each of BTS is placed on a Cartesian coordinate system of BTS $_{i}\left(\mathrm{XBTS}_{i}, \mathrm{YBTS}_{i}\right)$ and distance $\mathrm{d}_{\mathrm{i}, \mathrm{k}}$ is the distance from the MS to each k-th sample of BTS shown in equation 1, 2 and 3 (Pinem and Fauzi, 2018).

$$
\begin{aligned}
& d_{i, k}=\sqrt{\left(X_{k}-X_{B T S_{i}}\right)^{2}+\left(Y_{k}-Y_{B T S_{i}}\right)^{2}} \\
& X_{k}=r \cos \theta_{k-1}+X_{k-1} \\
& Y_{k}=r \sin \theta_{k-1}+Y_{k-1}
\end{aligned}
$$

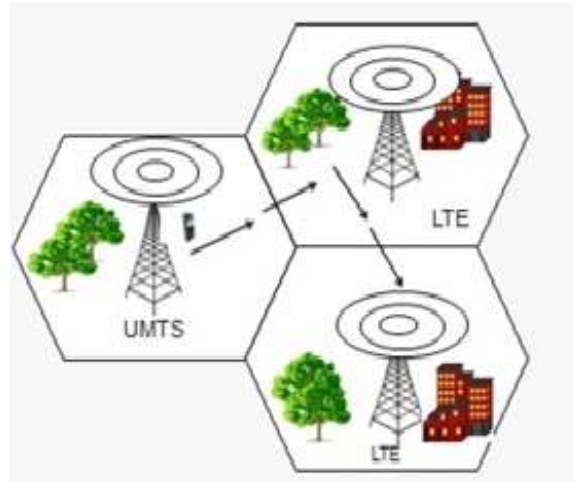

Fig.1. System model

The RSCP (Received Signal Code Power) and RSRP (Reference Signal Received Power) are the propagation parameters that are measured and observed. The received pilot signal strength (RSS) based handover are employed where hysteresis-threshold is chosen as soft handover algorithm.

The UMTS network uses Maximum Allowable Path Loss(MAPL) to determine maximum propagation loss. The link budget employed in this simulation is taken from (Sauter, 2011)as shown in Table 1.

Table 1. UMTS link budget

\begin{tabular}{cc}
\hline Parameter & UM \\
& TS \\
\hline Transmitter - Node B \\
\hline Tx Power (dBm) & 2,542 \\
&, 474 \\
\hline Tx antenna Gain $(\mathrm{dBi})$ & 1,742 \\
\hline
\end{tabular}




\begin{tabular}{lc}
\hline & \multicolumn{1}{c}{531} \\
\hline Cable Loss $(\mathrm{dB})$ & 2 \\
\hline EIRP $(\mathrm{dBm})$ & 4,685 \\
&, 005 \\
\hline \multicolumn{1}{c}{ Receiver - UE } & \\
\hline Thermal noise density $(\mathrm{dBm} / \mathrm{Hz})$ & -174 \\
\hline Receiver noise figure $(\mathrm{dB})$ & 8 \\
\hline Receiver noise density $(\mathrm{dB})$ & -166 \\
\hline Receiver noise power $(\mathrm{dBm})$ & - \\
& 100.16 \\
\hline Spreading Gain $(\mathrm{dB})$ & 24.98 \\
\hline Required Eb/No (dB) & 7 \\
\hline Interference Margin $(\mathrm{dB})$ & 6.02 \\
\hline Required signal power $(\mathrm{dBm})$ & - \\
& 112.17 \\
\hline Softhandover Gain $(\mathrm{dB})$ & 1 \\
\hline Shadow fading std dev.(dB) & 6 \\
\hline Shadow fading margin $(\mathrm{dB})$ & 7.2 \\
\hline \multicolumn{1}{c}{ Maximum Path Loss } & 146.4 \\
\hline
\end{tabular}

The radius of BTS is obtained by using Cost 231 model shown in equation 4 and 5(Rappaport, 2002).

$R_{m=10} \frac{M A P L-46,3-33,9 \log f c+13,82 \operatorname{logh} t+a(h r)-3(h r)}{44,9-6,55 \operatorname{logh} t} \times 100$

$a(h r)=3,2(\log 11,75 h r)^{2}-4,97 d B$

The MAPL on LTE is based on parameters shown in Table 2(Sainju, 2002). The radius of BTS is obtained by using Erceg Greenstein model show in equation 6(Rappaport, 2002).

Table 2. LTE link budget

\begin{tabular}{lc}
\multicolumn{2}{c}{ Table 2. LTE link budget } \\
\hline \multicolumn{1}{c}{ Parameter } & L \\
& TE \\
\hline \multicolumn{2}{c}{ Transmitter - eNode B } \\
\hline Tx Power (dBm) & \multicolumn{1}{c}{6} \\
\hline Tx antenna Gain (dBi) & \multicolumn{1}{c}{8} \\
\hline Cable Loss (dB) & 6 \\
\hline EIRP (dBm) & 2 \\
\hline \multicolumn{1}{c}{ Receiver - UE } & - \\
\hline UE Noise Figure (dB) & 104.5 \\
\hline Thermal Noise (dB) & - \\
\hline Receiver noise floor (dBm) & 97.5 \\
\hline
\end{tabular}




\begin{tabular}{lr}
\hline SINR(dB) & -9 \\
\hline Receiver Sensitivity $(\mathrm{dBm})$ & - \\
& 106.5 \\
\hline Interference Margin $(\mathrm{dB})$ & 4 \\
\hline Control Channel Overhead $(\%)$ & 2 \\
& 0 \\
\hline Rx Antenna Gain $(\mathrm{dBi})$ & 0 \\
\hline Body Loss $(\mathrm{dB})$ & 0 \\
\hline \multicolumn{1}{c}{ Maximum Path Loss } & 1 \\
& 63.5 \\
\hline
\end{tabular}

$R_{m}=10 \frac{M A P L-80,76-15,81-6 \log \left(\frac{f}{2000}\right)-\left(-10,8 \log \left(\frac{h t}{2}\right)\right)}{43,75} \times 100$

The simulation by using RSS based handover method is implemented inUMTS-LTE network. The UMTS handover parameter is RSCP. RSCPis determined by usingEquation 7(Halgamuge, 2006).

$\mathrm{RSCP}=$ Ptx_UMTS + Gain_UMTS $-\mathrm{L}_{\text {feederTx }}-$ Pathloss + Ec/Io $(\mathrm{dB})$

Where for Gain_umts is $18 \mathrm{dBi}$ and $\mathrm{L}_{\text {feederTx }}$ is $2 \mathrm{~dB}$. The pathloss shown in equation 8 and 9(Halgamuge, 2006).

Pathloss $=46,3+(33,9 \cdot \log (\mathrm{f}))-\left(13,82 \log \left(\mathrm{h}_{\mathrm{b}}\right) \alpha+\left(\left(44,9-6,55 \log \left(\mathrm{h}_{\mathrm{b}}\right)\right) \log (\mathrm{d})\right)+3\right.$

$\left(\frac{E_{c}}{I_{o}}\right)=\frac{P_{\text {pilot. }} r_{1}{ }^{-\alpha} 10^{\frac{\zeta 1}{10}}}{N_{t h}+P_{T 1 .}(1-\alpha) r_{1}-\alpha 10^{\frac{\zeta 1}{10}}+\sum_{k=2}^{M} P_{T k r_{k}-\alpha^{10}} \frac{\zeta k}{10}}(9)$

Urban area $\alpha=4$ and shadowing $(\zeta)$ is $8-10 \mathrm{~dB}$. The correlation between the pilot signal power $\left(\mathrm{P}_{\text {pilot }}\right)$ with the transmit power $\left(\mathrm{P}_{\mathrm{T}}\right)$ Node $\mathrm{B}$ shown in equations 10 (Chen, 2003).

$P_{\text {pilot }}=(1-\gamma) P_{T}$

Where $\gamma$ is the power allocated for the traffic channel. If $\mathrm{P}_{\mathrm{T}}$ is assumed to be the same for all NodeBs, and $\mathrm{N}_{\text {th }}$ is assumed to be much less than of interference receivedtoUE shown in equation 11 .

$\left(\frac{E_{c}}{I_{o}}\right)=\frac{(1-\gamma)}{(1-\alpha)+\sum_{k=2}^{M}\left(\frac{r_{k}}{r_{1}}\right) \cdot{ }^{-\alpha} 10^{\frac{\zeta k-\zeta 1}{10}}}$

The RSRP is employed to determine cell selection, cell reselection, and handover. The value is approximated by equation 12(Sauter, 2011). Fading and path loss are determined by equation 13 and 14(Chen, 2003).

$\mathrm{RSRP}=\mathrm{EIRP}_{- \text {Pathloss }_{(\text {to UE })}+\text { Shadow Fading }_{(\sigma=3)}}$ 
Shadow Fading $=\frac{\mathrm{e}-\frac{\left[(\mathrm{M}-\mathrm{m})^{2}\right]}{2 \sigma}}{3(2 \pi)^{1 / 2}}$

Pathloss $=\mathrm{A}+\left(10 \times \mathrm{x} \times \log \left(\frac{\mathrm{d}}{100}\right)\right)+$ Shadow Fading $+\mathrm{k}_{\mathrm{f}}+k_{r}$

The soft handover algorithm is designed as follows:

1. If the active set contains BTS1, $\hat{S}_{1}(\mathrm{~d})>\hat{\mathrm{S}}_{\min }$ and absolute difference of $\hat{\mathrm{S}}_{1}(\mathrm{~d})$ and $\hat{\mathrm{S}}_{2}(\mathrm{~d})$ is higher than hysteresis value HYST_ADD, then active set stays in BS1.

2. If $\hat{\mathrm{S}}_{1}(\mathrm{~d})$ and $\hat{\mathrm{S}}_{2}(\mathrm{~d})>\hat{\mathrm{S}}_{\mathrm{min}}$ and absolute difference of $\hat{\mathrm{S}}_{1}(\mathrm{~d})$ and $\hat{\mathrm{S}}_{2}(\mathrm{~d})$ is lower than HYST ADD, then active set is BTS 1BTS 2.

3. If $\hat{\mathrm{S}}_{1}(\mathrm{~d})$ and $\hat{\mathrm{S}}_{2}(\mathrm{~d})>\hat{\mathrm{S}}_{\min }$, the absolute difference is higher than HYST_DROP, thenis BTS 2.

4. If $\hat{\mathrm{S}}_{1}(\mathrm{~d})$ and $\hat{\mathrm{S}}_{2}(\mathrm{~d})<\hat{\mathrm{S}}_{\text {min }}$ then active set are not either BTS1 or BTS2.

In the simulation, it is assumed that BTS 1 is part of UMTS network while BTS 2 and BTS 3 are LTE and then the input parameters used in the system model are shown in Table 5.

Table 5. Parameter input

\begin{tabular}{lc}
\multicolumn{1}{c}{ Parameter input } & Nilai \\
\hline MAPL UMTS & 146,465 \\
\hline MAPL LTE & 163,5 \\
\hline Frekuensi (MHz) & 2100 \\
& $\& 2600$ \\
\hline EIRP UMTS $(\mathrm{dBm})$ & 40,85 \\
\hline EIRP LTE $(\mathrm{dBm})$ & 62 \\
\hline Height ofantenna $(\mathrm{m})$ & 1,5 \\
\hline Height ofbase station $(\mathrm{m})$ & 30 \\
\hline Threshold UMTS $(\mathrm{dB})$ & -100 \\
\hline Threshold LTE $(\mathrm{dB})$ & -113 \\
\hline Hysteresis ADD $(\mathrm{dB})$ & 8 \\
\hline Hysteresis Drop $(\mathrm{dB})$ & 10 \\
\hline Distance MS to BTS $(\mathrm{m})$ & 8000 \\
\hline Sampling time $(\mathrm{s})$ & 1 \\
\hline Speed $(\mathrm{m} / \mathrm{s})$ & 2 \\
\hline Iteration & 1 \\
\hline
\end{tabular}

\section{RESULTS}

The design model system that has been implemented in Matlab is shown in Figure 2. 


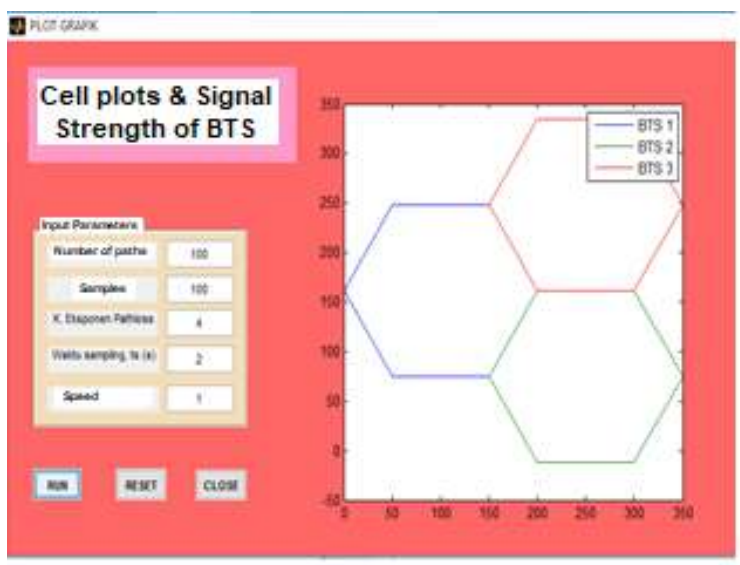

Fig.2. System Model

The RSCP values on UMTS network decrease as distant from BTS increases. It is about $0 \mathrm{dBm}$ when closes to BTS, but decreases exponentially when moves away from BTS. The plot is in Figure 3.

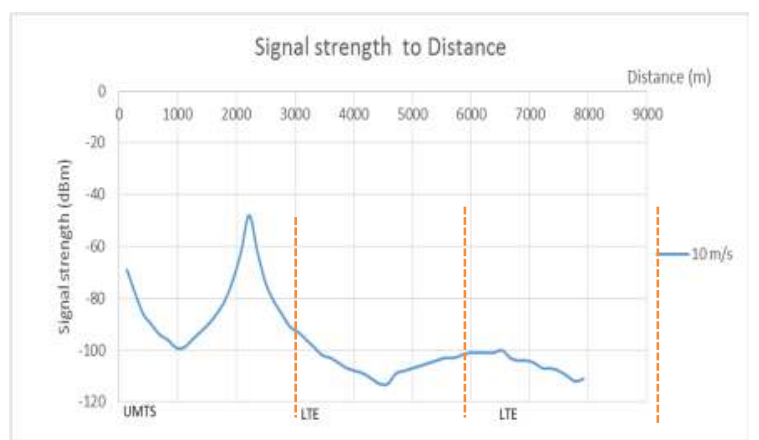

Fig.3. Signal strength to distance at $\mathrm{v}=10 \mathrm{~m} / \mathrm{s}$

Figure 3shows the distance traveled from 0 to $8000 \mathrm{~m}$, where at a distance up to 1000 meters is still connected by the BTS 1 of UMTS network. By determining the threshold value of $-100 \mathrm{dBm}$ for UMTS, the RSCP is $-99 \mathrm{dBm}$, while in LTE the threshold value is -113 $\mathrm{dBm}$, so the RSRP value is $-111 \mathrm{dBm}$. Figure 3 also showsthatthe distance that can be handled by UMTS (BTS 1) is up to $1000 \mathrm{~m}$. Distance of $2000 \mathrm{~m}$ to $5000 \mathrm{~m}$ is handled by BTS 2.Distance $5000 \mathrm{~m}$ to $8000 \mathrm{~m}$ is handled by BTS 3. The signal strength is shown in Figure 4. 


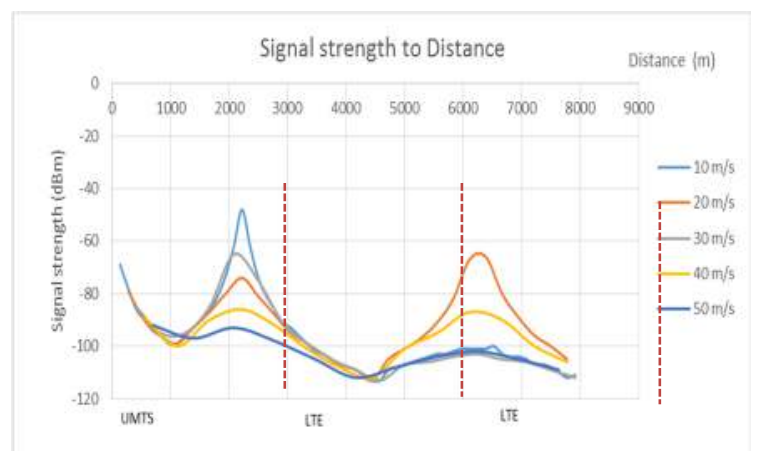

Fig.4. Signal strength to distance on $v=10 \mathrm{~m} / \mathrm{s}, \mathrm{v}=20 \mathrm{~m} / \mathrm{s}, \mathrm{v}=30 \mathrm{~m} / \mathrm{s}, \mathrm{v}=40 \mathrm{~m} / \mathrm{s}$ and $\mathrm{v}=50$ $\mathrm{m} / \mathrm{s}$

Figure 4 shows that RSCP and RSRP of various speed have different values. The greater the speed,the sorter the distance travelled. It is shown by the smaller sampling value. Table 4 plots the values.

Table 4. Signal strength for different speeds.

\begin{tabular}{cccc}
\hline $\begin{array}{c}\text { Distance } \\
(\mathrm{v})\end{array}$ & RSCP $(\mathrm{dBm})$ & RSRP $(\mathrm{dBm})$ & $\begin{array}{c}\text { Sampling } \\
(\mathrm{N})\end{array}$ \\
\hline $\mathrm{v}=10 \mathrm{~m} / \mathrm{s}$ & -99 & -111 & 57 \\
\hline $\mathrm{v}=20 \mathrm{~m} / \mathrm{s}$ & -99 & -105 & 28 \\
\hline $\mathrm{v}=30 \mathrm{~m} / \mathrm{s}$ & -95 & -107 & 19 \\
\hline $\mathrm{v}=40 \mathrm{~m} / \mathrm{s}$ & -97 & -112 & 14 \\
\hline $\mathrm{v}=50 \mathrm{~m} / \mathrm{s}$ & -97 & -112 & 11 \\
\hline
\end{tabular}

Table 4 shows the sampling at different speeds. Figure 5 shows the relationship betweenhandover numberand speed. The number of handover tends to increase when speed increases.At speed $\mathrm{v}=10 \mathrm{~m} / \mathrm{s}$, handover occurstwice. It increases to three times for speed of $40 \mathrm{~m} / \mathrm{s}$.

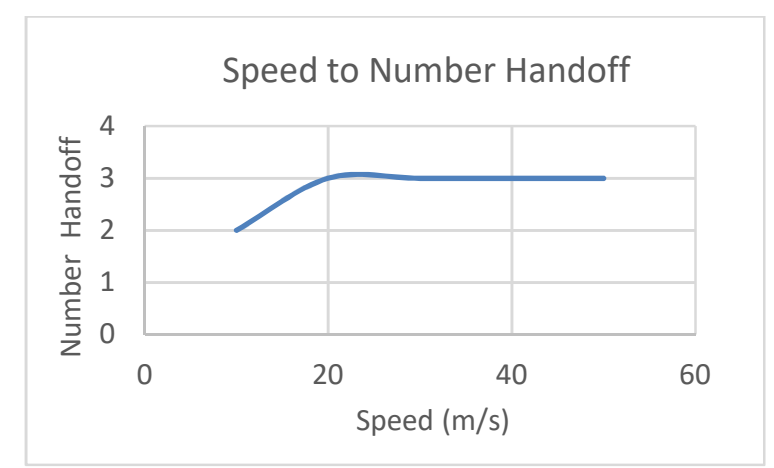

Fig.5. Speed and number of handover

Figure 6 shows the signal strength of the UMTS-LTE network for 3 BTS. Thehandover occurs when MS moving at speed of $10 \mathrm{~m} / \mathrm{s}$. 


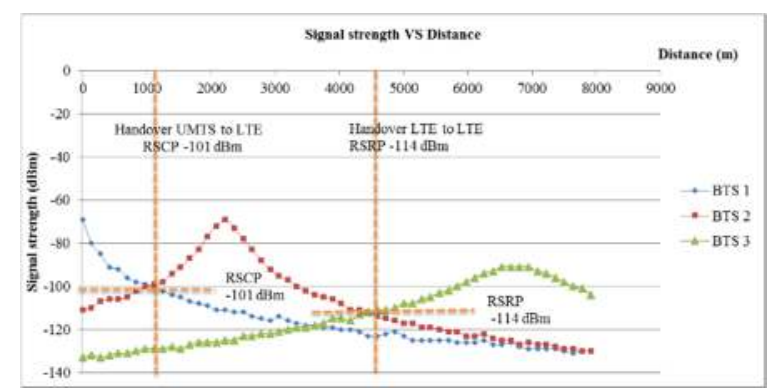

Fig.6. Handover at 3 BTS and soft handover performance in UMTS-LTE

Figure 6 shows that at distance of $1250 \mathrm{~m}$, handover occurs in BTS 1 withRSCP -101 $\mathrm{dBm}$, sampling point 10 and active set is BS 2 with RSRP $-98 \mathrm{dBm}$. BS 2 to BS3 handover happens at distanceof $4583.33 \mathrm{~m}$ with RSRP $-114 \mathrm{dBm}$. The sampling point 34 and active set is BS 3 with RSRP $-111 \mathrm{dBm}$.

\section{Conclusions}

It can be concluded that among the propagation parameters that affect the performance of soft handover on UMTS-LTE network is the sampling point and speed. The greater the speed, the lower the point of sampling, and the more frequent the handover. It was found that $10 \mathrm{~m} / \mathrm{s}$ is the best speed as the RSCP and RSRP signal strength are $-99 \mathrm{dBm}$ and $-111 \mathrm{dBm}$ respectively with the number of sampling points 57 and the number of handing over is 2 times.

\section{References}

[1] Chen, Y. (2003) Soft Handover Issues in Radio Resource Management for $3 G$ WCDMA Networks. Queen Mary, University of London.

[2] Halgamuge, M. N. (2006) 'Performance Evaluation and Enhancement of Mobile and Sensor Networks', in -.

[3] Kalbande, H. D. and D. (2014) 'Review of Mobile Data off loading through Wi-Fi', in Internasional Conference on Circuits, Systems, Communication and Information Technology.

[4] Marwan Al-Akaidi, S. (2015) 'A transport layer protocol for uplink WiMAX video streaming', International Journal of Multimedia and Ubiquittous Engineering, 10(1), pp. 19-32.

[5] Pinem, M. (2014) 'Evaluation of the Optimal Handoff Parameters using the Method of Threshold with Hysteresis'. 
Pinem, M. and Fauzi, R. (2018) 'The effect of various parameters of large scale radio propagation models on improving performance mobile communications', IOP Conference Series: Materials Science and Engineering, 309(135), p. IOP Publishing.

Rappaport, T. S. (2002) Wireless Communication: Principles and Pratice. 2nd edn. New Jersey: Prentice Hall.

Sainju, P. M. (2002) LTE Performance Analysis on 800 and 1800 MHz Bands. Tampere University of Technology.

Sauter, M. (2011) From GSM to LTE an introduction to mobile networks and mobile broadband. Wley Inc.

Sravani, Mesala., S. S. and D. P. A. (2015) 'An Improved Vertical Handoff Algorithm for 4G Heterogeneous Wireless Networks', Int. Journal of Philosophie in computer science, $1(1)$.

Wardana Lingga, N. M. (2010) Teknologi wireless communication dan wireless broadband. Jogjakarta: Penerbit Andi. 